\title{
Reduced nitric oxide synthase and cyclo-oxygenase activity in the uterus of non-obese diabetic mice
}

\author{
Valeria Roca, Luciana Larocca, Mario Calafat, Julieta Aisemberg ${ }^{1}$, Roberto Meiss ${ }^{2}$, Ana M Franchi ${ }^{1}$ \\ and Claudia Pérez Leirós \\ Departamento de Química Biológica, Facultad de Ciencias Exactas y Naturales, Universidad de Buenos Aires, \\ CONICET, Buenos Aires, Argentina, ${ }^{1}$ Centro de Estudios Farmacológicos y Botánicos (CEFYBO), Universidad de \\ Buenos Aires, CONICET, Buenos Aires, Argentina and ${ }^{2}$ Academia Nacional de Medicina, Buenos Aires, Argentina \\ Correspondence should be addressed to C P Leirós who is now at Ciudad Universitaria, Pab. II, $4^{\circ}$ piso, 1428 Buenos Aires, \\ Argentina; Email: cpleiros@qb.fcen.uba.ar
}

\begin{abstract}
A functional interaction between progesterone, Th2 cytokines and a suitable balance between nitric oxide and prostaglandins in the uterus is considered to have a major role in the success of embryo implantation and pregnancy. Non-obese diabetic (NOD) mice offer a suitable model to study the modulatory role of Th1 cytokines on uterus signalling and function, since at the prediabetic stage they develop a spontaneous Th1 autoimmune response against exocrine glands similar to Sjögren's syndrome. Vasoactive intestinal peptide (VIP) is a vasoactive neuro- and immunopeptide that promotes Th2 profiles and contributes to the smooth muscle relaxation and vasodilation. The aim of the present study was to investigate the activities of nitric oxide synthase and cyclo-oxygenase and the effect of VIP in the uterus of NOD mice with an emerging Th1 cytokine response. We present evidence of a reduced basal and VIP-stimulated activity of both enzymes in the uterus of NOD mice compared with normal $B A L B / c$ mice in proestrus. An altered functional interaction between both enzymes is also present in NOD mice at the time when increased levels of serum interleukin (IL)-12 and tumour necrosis factor- $\alpha$ but not interferon (IFN)- $\gamma$ or IL-10 were detected. We conclude that signalling alterations in uteri of NOD mice are simultaneous to the onset of a systemic Th1 cytokine response. Reproduction (2006) 132 931-938
\end{abstract}

\section{Introduction}

Among the key factors that contribute to the success of embryonic implantation and pregnancy, progesterone levels, a Th2 cytokine profile and a suitable balance between nitric oxide and prostaglandins in the uterus have been assigned a critical role. Progesterone is central to the progression of the oestrous cycle and to the receptivity of the endometrium for embryo implantation. It is also known to modulate the Th1/Th2 cytokine profile in favour of Th2 cytokines (Szekeres-Bartho 2002). In line with this, patients with Th1 autoimmune diseases such as multiple sclerosis and rheumatoid arthritis improve during pregnancy (Nelson \& Ostensen 1997, Cutolo 2000, Olsen \& Kovacs 2002).

It has been proposed that optimal levels of nitric oxide are needed for implantation (Chwalisz et al. 1996, Purcell et al. 1999, Chwalisz \& Garfield 2000) and the establishment of pregnancy (Chwalisz et al. 1999). While nitric oxide synthase (NOS) immunoreactivity increases in rat endometrial and glandular epithelium in the periovulatory period contributing to uterine quiescence (Chatterjee et al. 1996, Ota et al. 1999), excessively high amounts are shown to impair embryo implantation causing embryonic resorption processes (Ogando et al. 2003). Constitutive NOS isoforms are activated by several physiological stimuli resulting in the production of low amounts of nitric oxide, while it is synthesized in vast amounts by the inducible NOS isoform (NOS II) upon the elicitation of inflammatory mediators (Moncada et al. 1991, MacMicking et al. 1997). The mechanism for nitric oxide regulation of implantation is still unclear, but recent supportive evidence indicates that it could act through the regulation of metalloproteases (Zhang et al. 2004) and cyclo-oxygenases (Wang \& Dey 2005), or by directly reducing uterine contractility (Bulletti \& de Ziegler 2005, Wang \& Dey 2005). A mutual regulation between nitric oxide synthase and cyclo-oxygenase (COX) in uterine tissue from mouse (Cella et al. 2006) and rat (Ribeiro et al. 2003) has been also shown.

The non-obese diabetic (NOD) mouse is a suitable model to study the progressive loss of exocrine secretion 
characteristic of Sjögren's syndrome, a chronic autoimmune disease that affects women in a 9:1 ratio. In the prediabetic stage, female mice of this strain provide a valuable tool to study the initiation and progression of the disease, since they display a progressive loss of salivary and lacrimal secretion and a spontaneous Th1 autoimmune response against exocrine glands (Robinson et al. 1996, van Blokland \& Versnel 2002). We have recently shown a loss of NOS activation in exocrine glands of prediabetic female NOD mice that parallels salivary dysfunction together with a lower response to vasoactive intestinal peptide (VIP) (Rosignoli et al. 2004, 2005).

Among various stimuli known to increase nitric oxide production thus modulating uterus quiescence, VIP might have an interesting role in some clinical situations where an inflammatory autoimmune disease underlies the course of pregnancy. Actually, VIP, a neuro- and immunopeptide that promotes secretion in glandular epithelium (Ekström et al. 1983, Inoue et al. 1985), contributes to the smooth muscle relaxation and vasodilation in the uterus through nitric oxide production (Clark et al. 1981, Jovanovic et al. 1998) and, similar to progesterone, it promotes Th2 cytokine production (Delgado etal. 2002). VIPacts through stimulation of constitutive NOS activity, prostaglandinmediated pathways and cAMP to inhibit uterine contractility (Ottesen et al. 1982, Murthy et al. 1993). In addition, VIP participates in the maternal regulation of embryonic growth (Gressens et al. 1998, Spong et al. 1999).

The aim of the present study was to investigate the activities of NOS and COX, two major enzymes involved in uterus function, in prediabetic NOD mice and the effect of VIP on both enzymes. We present evidence of a reduced basal and VIP-stimulated activity of both enzymes in the uterus of NOD mice in proestrus compared with normal BALB/C mice. The effect was coincident with an emerging Th1 cytokine profile in the serum but not in the uterus of NOD mice.

\section{Materials and Methods}

\section{Animals}

$\mathrm{NOD}$ and BALB/C female mice were bred and maintained at the Central Animal Care facility of the School of Exact and Natural Sciences, University of Buenos Aires. They were maintained on a $12 \mathrm{~h}$ light: $12 \mathrm{~h}$ darkness schedule. Normally cycling non-pregnant mice of 15-16 weeks were fasted overnight with water ad libitum before being killed; tissues and blood were obtained and processed immediately after. For some experiments younger (10 weeks old) female mice were used. Mice were routinely tested for blood glucose levels (Wiener Lab., Rosario, Argentina) and considered pre-diabetic as their values of serum glucose on two occasions over a $24 \mathrm{~h}$ period did not significantly differ from those of the control mice $(1.0 \pm 0.1 \mathrm{~g} / \mathrm{l}, n=23)$. All studies were conducted according to standard protocols of the Animal Care and Use Committee of the School of Exact and Natural Sciences, University of Buenos Aires.

\section{Nitric oxide synthase activity}

NOS activity was measured in uteri using L-[U- $\left.-{ }^{14} \mathrm{C}\right]$ arginine as substrate as described earlier (Rosignoli et al. 2004). Each uterine horn was incubated separately with $0.2 \mu \mathrm{Ci}$ L- $\left[\mathrm{U}^{14}{ }^{14} \mathrm{C}\right]$ arginine (Amersham Pharmacia Biotech, about $300 \mathrm{mCi} / \mathrm{mmol}$ ) in $500 \mu \mathrm{l}$ Krebs-Ringer bicarbonate (KRB) solution $\mathrm{pH} 7.4$ gassed with $5 \% \mathrm{CO}_{2}$ in $\mathrm{O}_{2}$ at $37{ }^{\circ} \mathrm{C}$ for $30 \mathrm{~min}$. Then tissues were homogenized in $20 \mathrm{mM}$ Hepes pH 5.5 with $0.5 \mathrm{mM}$ EDTA, $1 \mathrm{mM}$ dithiothreitol (DTT) and $0.5 \mathrm{mM}$ EGTA, centrifuged at $10000 \mathrm{~g}$ for $10 \mathrm{~min}$ and $\left[{ }^{14} \mathrm{C}\right]$ citrulline in the supernatants was separated by ion exchange chromatography on AG $50 \mathrm{~W}$ resin (Bio-Rad). NOS activity was calculated as total activity minus that measured in the presence of $500 \mu \mathrm{M} \quad \mathrm{L}^{\mathrm{G}} \mathrm{N}^{\mathrm{G}}$-monomethyl arginine (L-NMMA) (Sigma). When used, VIP was added to one horn in the last $15 \mathrm{~min}$ at the final concentrations indicated and compared with the basal value of the other uterine horn in the absence of stimulus.

\section{Prostaglandin determination}

Prostaglandin E2 (PGE2) was quantified by specific RIA using rabbit antiserum (Sigma Chemical Co.) as previously described (Jaffe \& Behrman 1974). The sensitivity of the assay was $5-10 \mathrm{pg} / \mathrm{ml}$ and the cross-reactivity was less than $0.1 \%$ with other prostaglandins. Intra- and inter-assay variations were each $<8.0 \%$. Results were expressed as nanograms prostaglandins synthesized during $1 \mathrm{~h} / \mathrm{mg}$ protein. Briefly, uterus containing both myometrium and endometrium was removed, immediately cleaned of fat and rinsed thoroughly in cold Krebs-Ringer bicarbonate buffer (KRB) for PGE2 determination. Uterus from each mouse was incubated in a KRB buffer for 60 min at $37{ }^{\circ} \mathrm{C}$ and prostaglandins extracted by previous acidification of the supernatant to $\mathrm{pH} 3$ with $1 \mathrm{~N} \mathrm{HCl}$. After being extracted twice with $2 \mathrm{ml}$ ethyl acetate, prostaglandins were dried under nitrogen, resuspended in RIA buffer and measured immediately. An aliquot of homogenized uteri was used for measuring the total protein content. When used, VIP was added from the beginning of the incubation time at the final concentrations indicated.

\section{Immunoblotting}

Uteri were excised out and individually homogenized at $4{ }^{\circ} \mathrm{C}$ in $50 \mathrm{mM}$ Tris-HCl buffer $\mathrm{pH} 7.5$ with $0.15 \%$ Triton X-100 and protease inhibitors as previously reported for exocrine tissues (Rosignoli \& Perez Leiros 2002). Once centrifuged at $5000 \mathrm{~g} 10 \mathrm{~min}$ at $4{ }^{\circ} \mathrm{C}$, supernatants were frozen at $-80{ }^{\circ} \mathrm{C}$ until used and an aliquot of each 
sample was separated for protein determination. Extracts (100 $\mu \mathrm{g}$ protein/lane), positive controls and molecular weight standards (Amersham Pharmacia Biotech Inc.) were subjected to $7.5 \%$ SDS-PAGE, transferred to nitrocellulose membranes and revealed with specific monoclonal antibodies against NOS I, NOS II or NOS III (BD, Transduction Labs, KY, USA) or subjected to $10 \%$ SDS-PAGE, transferred and revealed with $M A B$ against COX-1 and polyclonal antibody against COX-2 (Santa Cruz, CA, USA) using biotinylated secondary antibodies and streptavidin-peroxidase complex (DAKO), as we have described earlier (Rosignoli et al. 2004).

\section{Immunohistochemistry}

Uteri from NOD and BALB/c mice were fixed in $4 \%$ paraformaldehyde overnight at $4{ }^{\circ} \mathrm{C}$. The tissues were embedded in paraffin wax and sections of $4 \mu \mathrm{m}$ were cut and placed on silanized glass slides. The immunoperoxidase staining kit Ldab2 (DAKO) was used according to the protocol recommended by the manufacturer. Briefly, tissue sections were de-paraffinized, rehydrated in buffer, endogenous peroxidase activity of the tissues was quenched with $0.1 \%$ hydrogen peroxide in methanol for $30 \mathrm{~min}$. The sections were incubated overnight at room temperature with the primary antibodies diluted 1:250 for NOS isoforms and COX-2, and 1:400 for COX-1 in PBS. Control sections without primary antibody served as control. Biotinylated secondary antibodies were added and the sections incubated for $1 \mathrm{~h}$. The sections were then incubated with streptavidin peroxidase complex for $30 \mathrm{~min}$ and sections were washed 3 times for $5 \mathrm{~min}$ in PBS. Finally, diaminobenzidine (DAKO) was used as the peroxidase substrate, and the tissue sections were counterstained with haematoxylin.

\section{Cytokine measurements}

Serum from each animal was isolated by centrifugation at $900 \mathrm{~g} 10 \mathrm{~min}$ at $4{ }^{\circ} \mathrm{C}$ and stored at $-80{ }^{\circ} \mathrm{C}$ until used. Uteri were excised out and individually homogenized at $4{ }^{\circ} \mathrm{C}$ in $50 \mathrm{mM}$ Tris- $\mathrm{HCl}$ buffer $\mathrm{pH} 7.5$ with protease inhibitors. Once centrifuged at $5000 \mathrm{~g}$ for $10 \mathrm{~min}$ at $4{ }^{\circ} \mathrm{C}$, supernatants were frozen at $-80{ }^{\circ} \mathrm{C}$ until used and an aliquot of each sample was separated for protein determination. Cytokines were determined with a capture ELISA assay as previously described (Juarranz et al. 2004). Briefly, microtitre plates (Corning Inc., New York, USA) were coated with a capture monoclonal anti-mouse IL-10, TNF- $\alpha$, IL-12 or IFN $\gamma$ antibody (Pharmingen, San Diego, CA, USA) at $2 \mu \mathrm{g} / \mathrm{ml}$ at $4{ }^{\circ} \mathrm{C}$. After washing and blocking with PBS containing $3 \%$ BSA, sera were added for $12 \mathrm{~h}$. Unbound material was washed off and biotinylated monoclonal anti-IL-10, TNF- $\alpha$, IL-12 or IFN- $\gamma$ antibodies (Pharmingen) were added at $2 \mu \mathrm{g} / \mathrm{ml}$ for $45 \mathrm{~min}$ and revealed with avidin-peroxidase and ABTS substrate solution (Sigma). The intra- and inter-assay variability for cytokine determination was $<5 \%$. The detection limits for serum samples were $15 \mathrm{pg} / \mathrm{ml}$ for IL-10 and TNF- $\alpha$ and $30 \mathrm{pg} / \mathrm{ml}$ for IL-12 and IFN $\gamma$; the values were expressed in picograms per millilitre of serum. The detection limit for tissue samples was $5 \mathrm{pg} / \mathrm{mg}$ protein for all cytokines.

\section{Statistical analysis}

Statistical significance of differences was determined by the two-tailed $t$-test for independent populations. When multiple comparisons were necessary, the StudentNewman-Keuls test was used after ANOVA. Differences between groups were considered significant at $P<0.05$.

\section{Results}

\section{NOS and COX activities and expression in NOD mice uteri}

NOS and COX activities were significantly lower in NOD mice uteri at proestrus compared with normal BALB/C mice (Fig. 1a and c). The activity of NOS was also assayed in younger NOD and BALB/C mice (10 weeks old) and the values were found similar to normal BALB/c of 16 weeks (NOS activity in uteri from 10 weeks old NOD mice in proestrus: $125 \pm 21 \mathrm{fmol} / \mathrm{mg}$ per $30 \mathrm{~min} ; n=4)$. To address whether expressional regulations of NOS and COX in uteri of NOD mice could account for the lower activity observed, the levels of the three isoforms of NOS and both isoforms of COX were determined in uteri of NOD and BALB/c mice. As it can be seen in Fig. 1b, both BALB/C and NOD mice presented the same pattern of NOS I and NOS III expression regardless of the oestrous stage studied. NOS II expression was undetectable at the same protein concentration tested for the other two isoforms. Similarly, Fig. $1 \mathrm{~d}$ shows no significant difference in the expressions of COX-1 and COX-2 between both mice strains. To further analyze cellular localization of the isoforms of NOS first detected by immunoblotting, NOS I and NOS III, and both isoforms of COX in NOD uteri, we performed immunohistochemical studies on uterine slices. Figure 2 shows that in both NOD and normal mice, the most intense staining for NOS I was found in stromal cells and myometrial tissue, while the endothelium of both endometrial and myometrial blood vessels displayed pronounced NOS III immunostaining. COX-1 and COX-2 were distributed in both endometrial and myometrial tissue as in normal mice (data not shown).

\section{NOS and COX activities in response to VIP}

The ability of VIP to stimulate nitric oxide and prostaglandin production in mice uteri was studied at the same stages of the oestrous cycle. Figure 3 right panel shows that VIP stimulated uterine NOS activity, while decreased 

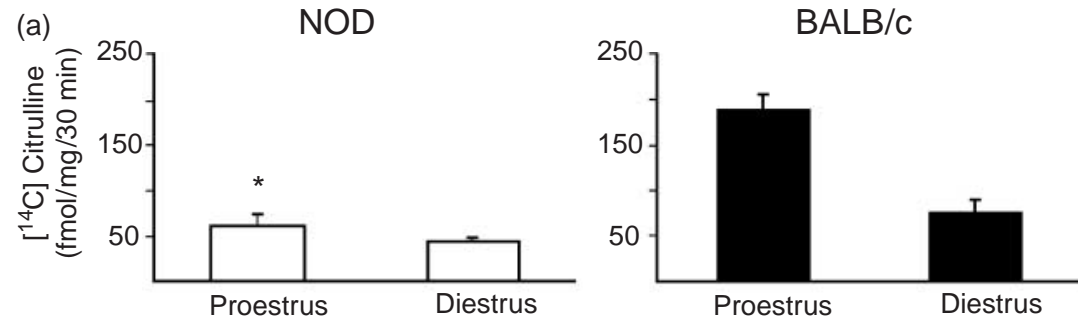

(b)
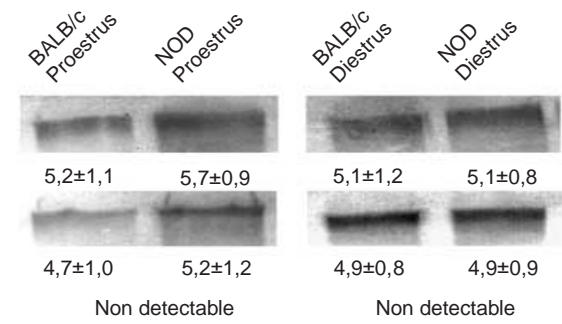

NOS I

NOS III

NOS II

(c)
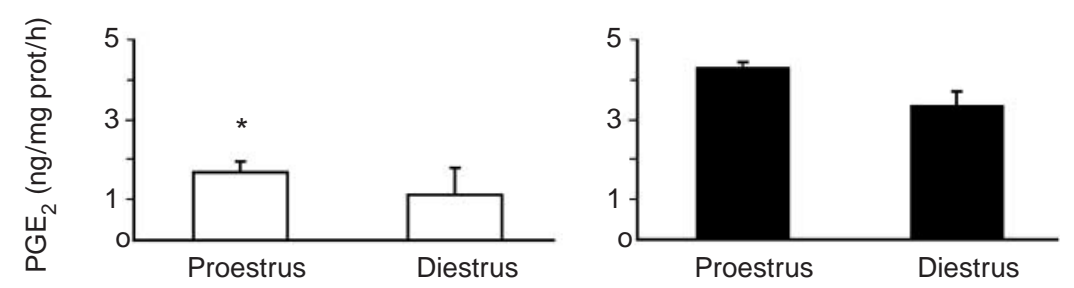

(d)
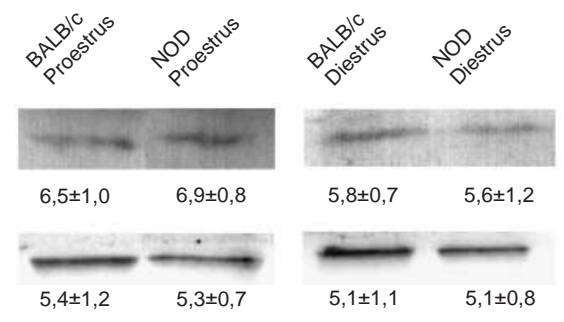

$\operatorname{cox} 1$

$\operatorname{cox} 2$
Figure 1 NOS and COX activities and expressions in the uterus of NOD mice (a) Basal NOS activity was determined in uteri of $\mathrm{NOD}$ and $\mathrm{BALB} / \mathrm{C}$ mice at different stages of the oestrous cycle as described in Materials and Methods. Estrus and metestrus values were similar to diestrus. Values represent the mean \pm s.E.M. of at least six different uteri. ${ }^{*} P<0.05$ vs basal value of $\mathrm{BALB} / \mathrm{C}$ mice in proestrus. (b) The expression of NOS isoforms in the uteri of NOD and control mice was assessed by immunoblotting as described in Materials and Methods. Blots shown are representative of five others. NOS II isoform was undetectable in both normal and NOD uteri. Values below each blot indicate the relative intensity of each band in arbitrary density units and represent the mean \pm S.E.M. of five blots. (c) Basal COX activity was determined in uteri of NOD and BALB/c mice at different stages of the oestrous cycle as described in Materials and Methods. Values represent the mean \pm S.E.M. of at least five different uteri. ${ }^{*} P<0.05$ vs basal value of $\mathrm{BALB} / \mathrm{C}$ mice in proestrus. (d) The expression of COX isoforms in the uteri of NOD and control mice was assessed by immunoblotting as described in Materials and Methods. Blots shown are representative of four others and quantification of band intensity was similar to (b) with values indicating the mean \pm S.E.M. of four blots. prostaglandin synthesis in normal mice. In contrast, VIP failed to activate NOS or reduce prostaglandin production in NOD uteri compared with normal mice (Fig. 3 left panel). An interaction between $\mathrm{NO}$ and prostaglandins was further tested by performing the activity assays in the presence of VIP with or without NOS and COX inhibitors (L-NMMA and indomethacine respectively). Indomethacine failed to modify VIP-stimulated NOS activity in either mice strain (Fig. 4a), while L-NMMA reversed the inhibitory effect of VIP on PGE2 accumulation in BALB/C mice but not in NOD mice (Fig. 4b).

\section{Cytokine concentrations}

On the knowledge that the reduced activities of both NOS and COX were evident in uteri from mice at 15-16 weeks of age in proestrus, we determined cytokine concentration in their serum at this stage. An underlying Th1 cytokine profile was evident in the sera of NOD mice, where increased levels of IL-12 and TNF- $\alpha$ could be observed. This profile was independent of the oestrous stage (data not shown). Serum IFN- $\gamma$ levels were undetectable in both NOD and normal mice sera and IL-10 showed no changes (Table 1). Cytokine levels determined in the sera of younger 10 weeks old NOD mice did not differ from normal BALB/c values (Rosignoli et al. 2005). The emerging Th1 profile observed systemically at 15-16 weeks of age was not seen locally in the uteri of NOD mice, where IFN- $\gamma$ and IL-10 levels were undetectable and IL-12 levels did not differ between BALB/C and NOD mice uteri (NOD IL-12 pg/ mg prot.: $13.4 \pm 2.8 ; n=4$; BALB/c: $10.0 \pm 2.5 ; n=4)$. 


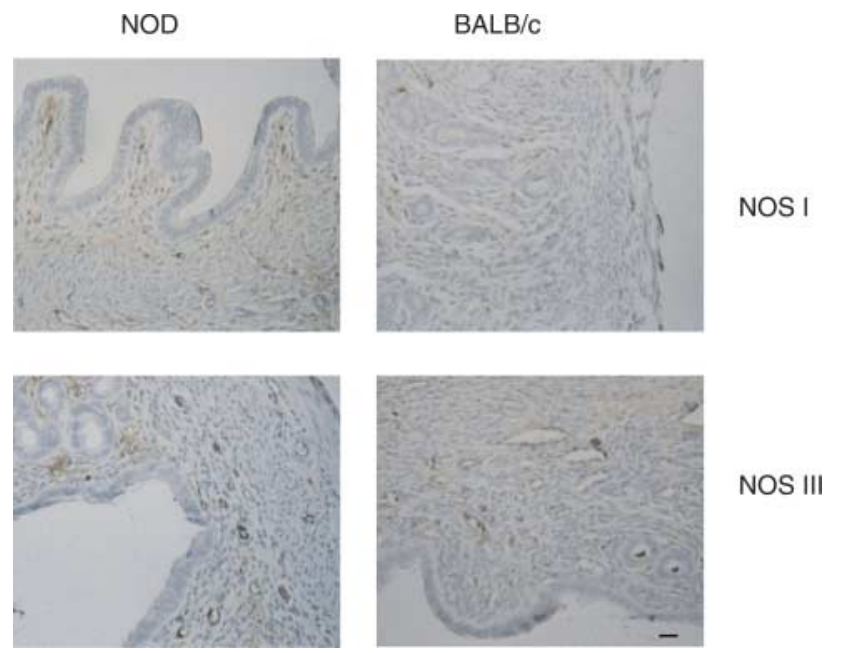

Figure 2 Localization of NOS in NOD mice uteri. Cellular localization of NOS I and NOS III in the uteri of NOD and control mice in proestrus was assessed by immunohistochemistry and counterstained with haematoxylin as described in Materials and Methods. Sections shown are representative of four other slices analyzed similarly, bar $=20 \mu \mathrm{m}$.

\section{Discussion}

We present evidence to indicate that uteri from normally cycling NOD mice display a lower activity of nitric oxide synthase and cyclo-oxygenase in basal and VIP-stimulated conditions compared with normal BALB/c mice. This functional alteration in NOD uteri is concomitant with an incipient Th1 cytokine response in the serum but not in the uterus. Our conclusions are supported by the following observations. First, NOD uteri synthesized less nitric oxide than BALB/C uteri in basal conditions in proestrus. The lower nitric oxide synthase activity of NOD uteri was not due to a lower expression or different localization of any of the isoforms of NOS. Similarly, PGE2 production was also defective in NOD uteri and again the effect could not be associated to a different COX-1 or COX-2 expression or localization. Second, VIP failed to stimulate nitric oxide or decrease PGE2 production as in normal uteri and a mutual interaction between these enzymes was not seen in NOD mice. Third, NOD mice that presented these uterine signalling alterations had increased levels of IL-12 and TNF- $\alpha$ in their sera, but showed no significant differences in the uterine cytokine profile.

A functional interaction between progesterone, Th2 cytokines and a suitable balance between nitric oxide and prostaglandins in the uterus is considered to have a major role in the success of embryonic implantation and pregnancy (Szekeres-Bartho \& Wegmann 1996, Hunt et al. 1997, Raghupathy 1997). Thus, embryonic resorption was associated with several conditions such as high nitric oxide and prostaglandin production in the uterus (Silver et al. 1995, Ogando et al. 2003), low progesterone levels (Elson \& Jurkovic 2004) or a Th1 cytokine profile (Chaouat et al. 1990).

We have previously reported on a defective nitric oxide production and signalling and a lower response to VIP in secretory glands of NOD mice (Rosignoli \& Perez Leiros 2002, Rosignoli et al. 2004). Here, we show that these defects are also present in the uterus and involve the activity of another key enzyme in reproductive tissues as COX. Both the lower activities of NOS and COX and the lower response to VIP might contribute to an up-regulation of uterine contractility and a loss of quiescence. The fact that the effects were detected in proestrus, characterized by high serum progesterone levels, suggests an additional role of this hormone in the effect. Regarding NOS and COX activities and expressions in the uterus of pregnant and non-pregnant rats, both enzymes are modulated by the progesterone levels and by the expression of progesterone receptors (Farina et al. 2001, 2004, Bulletti \& de Ziegler 2005).
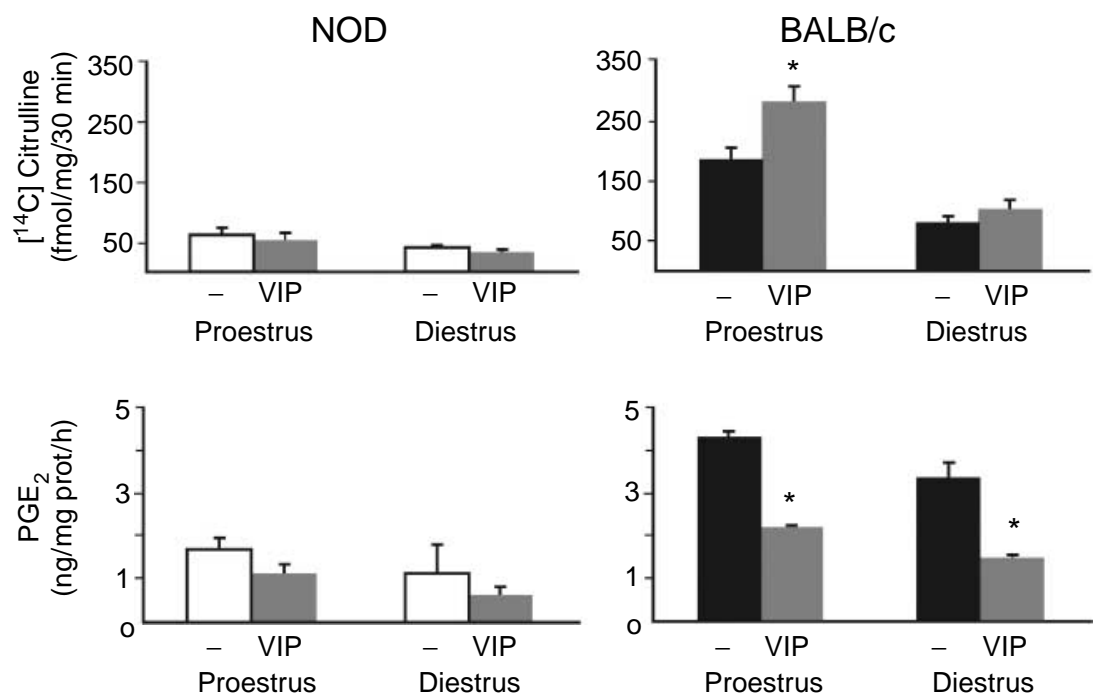

Figure 3 Effect of VIP on $\mathrm{NO}$ and prostaglandin production in NOD uteri. The effect of VIP $(10 \mathrm{nM})$ on NOS and COX activity was assessed in uteri of $\mathrm{NOD}$ and $\mathrm{BALB} / \mathrm{C}$ mice in proestrus and diestrus as described in Materials and Methods. Each value represents the mean \pm S.E.M. of at least four determinations. ${ }^{*} P<0.05$ vs basal values of $\mathrm{BALB} / \mathrm{C}$ mice in the same oestrous stage. 
(a)
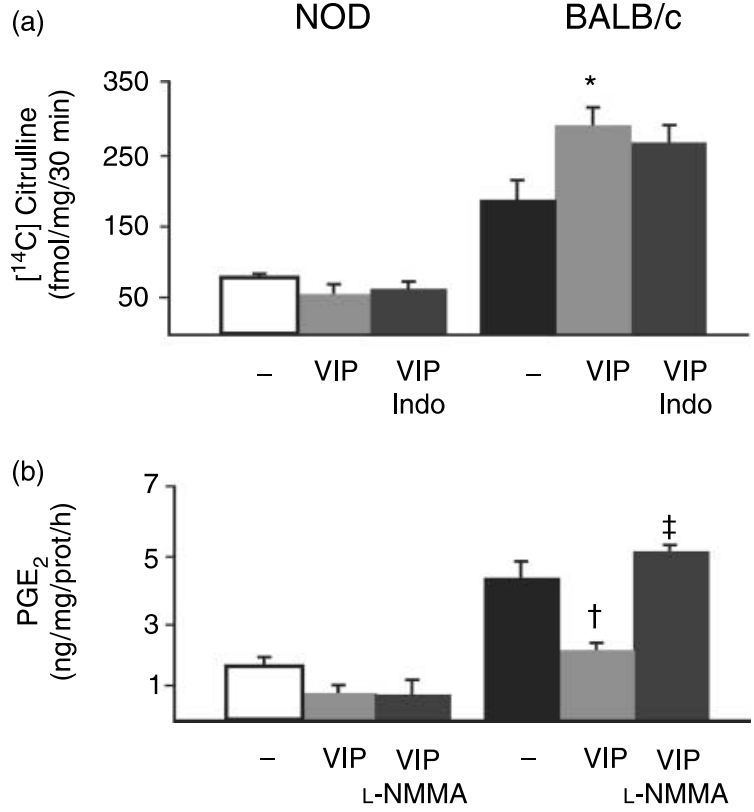

Figure $4 \mathrm{NO}$ and prostaglandin interaction in response to VIP. The effect of L-NMMA $(500 \mu \mathrm{M})$ or indomethacine $(1 \mu \mathrm{M})$ on NOS (a) and COX (b) activities in the presence of $10 \mathrm{nM}$ VIP was assessed in uteri of NOD and BALB/c mice in proestrus as described in Materials and Methods. Each value represents the mean \pm S.E.M. of at least four determinations. $* P<0.05$ vs basal value of $\mathrm{BALB} / \mathrm{C}$ mice, ${ }^{+} P<0.01$ vs basal value of BALB/c mice and ${ }^{\ddagger} P<0.01$ vs VIP in BALB/c mice.

Interestingly, prostaglandin synthesis is necessary for IL-1 $\beta$-mediated stimulation of progesterone secretion in luteal cells supporting an autocrine-paracrine mechanism (Miceli et al. 2003).

We have also shown a systemic increase of some Th1 cytokines that was not related to the oestrous stage and occurred in NOD mice simultaneously with uterine signalling alterations: IL-12 and TNF- $\alpha$, but not IFN- $\gamma$, were increased in the serum of NOD mice at 15-16 weeks of age indicating the onset of the Th1 response and confirming previous reports on the role of theses two cytokines at an early time to induce autoimmunity by priming inflammatory Th1 responses (Falcone \& Sarvetnick 1999). The fact that younger NOD mice (10 weeks

Table 1 Serum levels of cytokines.

\begin{tabular}{lllll}
\hline & \multicolumn{4}{c}{ Cytokines $(\mathrm{pg} / \mathrm{ml})$} \\
\cline { 2 - 5 } & \multicolumn{1}{c}{ IL-12 } & \multicolumn{1}{c}{ TNF- $\alpha$} & IL-10 & IFN- $\gamma$ \\
\hline NOD & $182 \pm 11^{*}$ & $223 \pm 21^{*}$ & $142 \pm 23$ & ND \\
BALB/C & $102 \pm 17$ & $104 \pm 5$ & $152 \pm 12$ & ND \\
\hline
\end{tabular}

Freshly isolated serum from each animal was individually processed and aliquoted for cytokine determination by a sandwich ELISA kit as described in Materials and Methods. No differences in cytokine levels were found between cycle stages in neither NOD nor BALB/c mice. Values are the mean \pm S.E.M. of at least five different sera from NOD or BALB/c mice. ${ }^{*} P<0.05$ vs. BALB/c. ND, undetectable. old) had normal NOS activity and normal cytokine levels in their serum further supports a priming role of this systemic immune response in the overall process. Progesterone can modulate cytokine levels favouring a Th2 profile (Szekeres-Bartho \& Wegmann 1996, Raghupathy 1997). Interestingly, it reduces IL-12 expression through the inhibition of arachidonic acid metabolism (Par et al. 2000). However, the converse has not been fully clarified as cytokines probably interact with progesterone synthesis in a systemic and more complex manner (Bornstein et al. 2004). Reports on Th1 autoimmune diseases like rheumatoid arthritis indicate that serum progesterone levels do not vary compared with normal subjects or were found decreased with a consequent decrease of the free androgen index (Valentino et al. 1993, Olsen \& Kovacs 2002, Rovensky et al. 2004, 2005). Regarding Sjögren's syndrome, no significant differences were observed in the levels of oestrogen and progesterone in sera between patients and controls although a higher oestrogen:progesterone relative ratio was reported (Taiym et al. 2004). Of interest, a lower progesterone concentration in the serum of prediabetic NOD mice has been observed when compared with normal control strains (Durant et al. 1998). It should be emphasized that not only the levels of circulating hormones but the expression and signalling through their receptors can be also rapidly regulated by changes in the immune-hormonal milieu during the course of chronic autoimmune disorders with such multifactorial origin.

With the aim of further analyzing the mechanism of NOS- and COX-deficient activities in NOD uteri, we explored the cellular localization of both enzymes in uterine tissue as well as the regulatory interaction between these enzymes and the local expression of cytokines in the tissue. Both NOS and COX isoforms were expressed in uteri to the same extent regardless of the oestrous stage or the level of activity displayed. Moreover, the enzymes presented a localization and immunostaining pattern comparable with normal mice and similar to other species. Taken together, these results rule out an expressional regulation of their activity (Chatterjee et al. 1996, Andronowska et al. 2005). Regarding the mutual regulation of their activities by the products of each other, we provided evidence of an interaction between NOS and COX in response to VIP that is not present in NOD mice. Neither the loss of enzyme activity, nor the regulatory failure seemed to be related to the local production of cytokines in uterine tissues, since there were no changes in their local levels. Moreover, uteri from younger NOD mice presented a normal pattern of NOS activity and expression when their serum levels of Th1 cytokines were still low. Accordingly, the increase of Th1 cytokines parallels the onset of uterine signalling alterations supporting a priming role of these mediators by means of a systemic rather than local effect. Although the mechanisms 
underlying these cellular and signalling alterations in NOD mice are not clarified at present, the ultimate effects of these alterations combined would be a loss of uterine quiescence that in turn would affect implantation and pregnancy. Further evidence will be necessary to assess if the differential serum cytokine profile in NOD mice at 15-16 weeks of age could account for NOS and COX defects in uterine tissues and if so, how this could influence NOD reproductive scores at later stages of disease. Also, a role of lower serum progesterone concentration in the onset of uterine and immune alterations in NOD mice should be further analyzed. A cross-talk between the immune and neuroendocrine systems might have a role in the loss of homeostatic control that precedes autoimmune diseases like Sjögren's syndrome. However, multiple immune-hormonal loops acting simultaneous and redundantly hinder the identification of individual effects of hormones and cytokines.

Finally, VIP might be an interesting immuneneuroendocrine mediator in this system as a modulator of the immune response through its selective antiinflammatory action on lymphocytes and macrophages on one side (Delgado et al. 2002), and the downregulatory effect on uterus contractility through prostaglandin-mediated pathways on the other (Ottesen et al. 1982). VIP levels vary in the uterus and deciduas at the early phases of implantation, and it has been assigned a role as a neural growth factor for the embryos (Gressens et al. 1998, Spong et al. 1999). In the light of these reports and the observations described here, it is conceivable that a defective VIP response in the uterus and/or the surrounding immune cells could result in a defective conditioning for successful implantation and pregnancy. The association of serum cytokine levels with biochemical alterations in uterine tissues as those reported here and the identification of the mechanisms underlying such functional interaction might be relevant for pregnancy in several immunopathological conditions as well as for the management of women with frequent miscarriage.

\section{Acknowledgements}

This work was supported by grants PICT 10901 from the ANPCYT and PIP 5638 from CONICET, Argentina. The authors declare that there is no conflict of interest that would prejudice the impartiality of this scientific work.

\section{References}

Andronowska A, Wasowska B, Calka J \& Doboszynska T 2005 Localization and correlation between NADPH-diaphorase and nitric oxide synthase isoforms in the porcine uterus during the estrous cycle. Cell and Tissue Research 321 243-250.
Bornstein SR, Rutkowski H \& Vrezas I 2004 Cytokines and steroidogenesis. Molecular and Cellular Endocrinology 215 135-141.

Bulletti C \& de Ziegler D 2005 Uterine contractility and embryo implantation. Current Opinion in Obstetrics \& Gynecology 17 265-276.

Cella M, Aisemberg J, Sordelli MS, Billi S, Farina M, Franchi AM \& Ribeiro ML 2006 Prostaglandins modulate nitric oxide synthase activity early in time in the uterus of estrogenized rat challenged with lipopolysaccharide. European Journal of Pharmacology 534 218-226.

Chaouat G, Menu E, Clark DA, Dy M, Minkowski M \& Wegmann TG 1990 Control of fetal survival in CBA x DBA/2 mice by lymphokine therapy. Journal of Reproduction and Fertility 89 447-458.

Chatterjee S, Gangula PR, Dong YL \& Yallampalli C 1996 Immunocytochemical localization of nitric oxide synthase-III in reproductive organs of female rats during the oestrous cycle. Histochemical Journal 28 715-723.

Chwalisz K \& Garfield RE 2000 Role of nitric oxide in implantation and menstruation. Human Reproduction 3 96-111.

Chwalisz K, Buhimschi I \& Garfield RE 1996 Role of nitric oxide in obstetrics. Prenatal and Neonatal Medicine 1 292-328.

Chwalisz K, Winterhager E, Thienel T \& Garfield RE 1999 Synergistic role of nitric oxide and progesterone during the establishment of pregnancy in the rat. Human Reproduction 14 542-552.

Clark KE, Mills EG, Stys SJ \& Seeds AE 1981 Effects of vasoactive polypeptides on the uterine vasculature. American Journal of Obstetrics and Gynecology 139 182-188.

Cutolo M 2000 Sex hormone adjuvant therapy in rheumatoid arthritis. Rheumatic Diseases Clinics of North America 26 881-895.

Delgado M, Abad C, Martinez C, Juarranz MG, Arranz A, Gomariz RP \& Leceta J 2002 Vasoactive intestinal peptide in the immune system: potential therapeutic role in inflammatory and autoimmune diseases. Journal of Molecular Medicine 80 16-24.

Durant S, Christeff N, Coulaud J, Nunez EA, Dardenne M \& HomoDelarche F 1998 Basal concentrations of various steroids in the nonobese diabetic (NOD) Mouse and effect of immobilization stress. Autoimmunity 28 249-258.

Ekström J, Mansson B \& Tobin G 1983 Vasoactive intestinal peptide evokes secretion of fluid and protein from rat salivary glands and the development of supersensitivity. Acta Physiologica Scandinavica 119 169-175.

Elson J \& Jurkovic D 2004 Biochemistry in diagnosis and management of abnormal early pregnancy. Current Opinion in Obstetrics \& Gynecology 16 339-344.

Falcone M \& Sarvetnick N 1999 Cytokines that regulate autoimmune responses. Current Opinion in Immunology 11 670-676.

Farina M, Ribeiro ML \& Franchi A 2001 Nitric oxide synthases in pregnant rat uterus. Reproduction 121 403-407.

Farina M, Ribeiro ML, Weissmann C, Estevez A, Billi S, Vercelli C \& Franchi A 2004 Biosynthesis and catabolism of prostaglandin F2alpha (PGF2alpha) are controlled by progesterone in the rat uterus during pregnancy. Journal of Steroid Biochemistry and Molecular Biology 91 211-218.

Gressens P, Paindaveine B, Hill JM, Evrard P \& Brenneman DE 1998 Vasoactive intestinal peptide shortens both $\mathrm{G} 1$ and $\mathrm{S}$ phases of neural cell cycle in whole postimplantation cultured mouse embryos. European Journal of Neuroscience 10 1734-1742.

Hunt JS, Miller L, Vassmer D \& Croy BA 1997 Expression of the inducible nitric oxide synthase gene in mouse uterine leukocytes and potential relationships with uterine function during pregnancy. Biology of Reproduction 57 827-836.

Inoue Y, Kaku K, Kaneko T, Yanahara N \& Kanno T 1985 Vasoactive intestinal peptide binding to specific receptors on rat parotid acinar cells induces amylase secretion accompanied by cyclic adenosine 3'-5'-monophosphate. Endocrinology 116 686-692.

Jaffe BM \& Behrman HR 1974 Methods of Hormone Radioimmunoassay, New York, USA: Academic Press. 
Jovanovic A, Jovanovic S, Tulic I \& Grbovic L 1998 Predominant role for nitric oxide in the relaxation induced by vasoactive intestinal polypeptide in human uterine artery. Molecular Human Reproduction 4 71-76.

Juarranz MG, Santiago B, Torroba M, Gutierrez-Cañas I, Palao G, Galindo M, Abad C, Martinez C, Leceta J, Pablos JL \& Gomariz RP 2004 Vasoactive intestinal peptide modulates proinflammatory mediator synthesis in osteoarthritic and rheumatoid synovial cells. Rheumatology 43 416-422.

MacMicking J, Xie QW \& Nathan C 1997 Nitric oxide and macrophage function. Annual Review of Immunology 15 323-350.

Miceli F, Tropea A, Minici F, Navarra P, Lanzone A \& Apa R 2003 Interleukin-1 beta stimulates progesterone production by in vitro human luteal cells: evidence of a mediatory role of prostaglandins. Journal of Clinical Endocrinology and Metabolism 88 2690-2694.

Moncada S, Palmer RMJ \& Higgs EA 1991 Nitric oxide physiology, pathophysiology and pharmacology. Pharmacological Reviews $\mathbf{4 3}$ 109-142.

Murthy KS, Zhang KM, Jin JG, Grider JR \& Makhlouf GM 1993 VIPmediated $\mathrm{G}$ protein-coupled $\mathrm{Ca}+2$ influx activates a constitutive NOS in dispersed gastric muscle cells. American Journal of Physiology 265 G660-G671.

Nelson JL \& Ostensen M 1997 Pregnancy and rheumatoid arthritis. Rheumatic Diseases Clinics of North America 23 195-212.

Ogando DG, Paz D, Cella M \& Franchi AM 2003 The fundamental role of increased production of nitric oxide in lipopolysacaride-induced embryonic resorption in mice. Reproduction 125 95-110.

Olsen NJ \& Kovacs WJ 2002 Hormones, pregnancy, and rheumatoid arthritis. Journal of Gender-Specific Medicine 5 28-37.

Ota H, Igarashi S, Oyama N, Suzuki Y \& Tanaka T 1999 Optimal levels of nitric oxide are crucial for implantation in mice. Reproduction, Fertility, and Development 11 183-188.

Ottesen B, Ulrichsen H, Fahrenkrug J, Larsen JJ, Wagner G, Schierup L \& Sondergaard F 1982 Vasoactive intestinal polypeptide and the female genital tract: relationship to reproductive phase and delivery. American Journal of Obstetrics and Gynecology 143 414-420.

Par G, Bartok B \& Szekeres-Bartho J 2000 Cyclooxygenase is involved in the effects of progesterone-induced blocking factor on the production of interleukin 12. American Journal of Obstetrics and Gynecology 183 126-130.

Purcell TL, Given R, Chwalisz K \& Garfield RE 1999 Nitric oxide synthase distribution during implantation in the mouse. Molecular Human Reproduction 5 467-475.

Raghupathy R 1997 Th1-type immunity is incompatible with successful pregnancy. Immunology Today 18 478-482.

Ribeiro ML, Cella M, Farina M \& Franchi A 2003 Crosstalk between nitric oxide synthase and cyclooxygenase metabolites in the estrogenized rat uterus. Prostaglandins, Leukotrienes, and Essential Fatty Acids 4 285-290.

Robinson CP, Yamamoto H, Peck AB \& Humphreys-Beher MG 1996 Genetically programmed development of salivary gland abnormalities in the NOD (non obese diabetic)-scid mouse in the absence of detectable lymphocytic infiltration: a potential trigger for sialoadenitis of NOD mice. Clinical Immunology and Immunopathology 79 50-59.
Rosignoli F \& Perez Leiros C 2002 Nitric oxide synthase I and VIPactivated signaling are affected in salivary glands of NOD mice. Journal of Neuroimmunology 130 109-116.

Rosignoli F, Roca V, Meiss R, Pregi N \& Pérez Leirós C 2004 Inhibition of calcium-calmodulin kinase restores nitric oxide production and signaling in submandibular glands of a mouse model of salivary dysfunction. British Journal of Pharmacology 143 1058-1065.

Rosignoli F, Roca V, Meiss R, Leceta J, Gomariz RP \& Pérez Leirós C 2005 Defective signalling in salivary glands precedes the autoimmune response in the non-obese diabetic mouse model of sialadenitis. Clinical and Experimental Immunology 142 411-418.

Rovensky J, Radikova Z, Imrich R, Greguska O, Vigas M \& Macho L 2004 Gonadal and adrenal steroid hormones in plasma and synovial fluid of patients with rheumatoid arthritis. Endocrine Regulations 38 143-149.

Rovensky J, Kvetnansky R, Radikova Z, Imrich R, Greguska O, Vigas M \& Macho L 2005 Hormone concentrations in synovial fluid of patients with rheumatoid arthritis. Clinical and Experimental Rheumatology 23 292-296.

Silver RM, Edwin SS, Trautman MS, Simmons DL, Branch DW, Dudley DJ \& Mitchell MD 1995 Bacterial lipopolysaccharidemediated fetal death. Production of a newly recognized form of inducible cyclooxygenase (COX-2) in murine decidua in response to lipopolysaccharide. Journal of Clinical Investigation 95 725-731.

Spong CY, Lee SJ, McCune SK, Gibney G, Abebe DT, Alvero R, Brenneman DE \& Hill JM 1999 Maternal regulation of embryonic growth: the role of vasoactive intestinal peptide. Endocrinology $\mathbf{1 4 0}$ 917-924.

Szekeres-Bartho J 2002 Immunological relationship between the mother and the fetus. International Reviews of Immunology $\mathbf{2 1}$ 471-495.

Szekeres-Bartho J \& Wegmann TG 1996 A progesterone-dependent immunomodulatory protein alters the Th1/Th2 balance. Journal of Reproductive Immunology 31 81-95.

Taiym S, Haghighat N \& Al-Hashimi I 2004 A comparison of the hormone levels in patients with Sjogren's syndrome and healthy controls. Oral Surgery, Oral Medicine, Oral Pathology, Oral Radiology, and Endodontics 97 579-583.

Valentino R, Savastano S, Tommaselli AP, Riccio A, Mariniello P, Pronesti G, De Divitiis PM \& Lombardi G 1993 Hormonal pattern in women affected by rheumatoid arthritis. Journal of Endocrinological Investigation 16 619-624.

van Blokland SC \& Versnel MA 2002 Pathogenesis of Sjogren's syndrome: characteristics of different mouse models for autoimmune exocrinopathy. Clinical Immunology 103 111-124.

Wang H \& Dey SK 2005 Lipid signaling in embryo implantation. Prostaglandins \& Other Lipid Mediators 77 84-102.

Zhang X, Wang HM, Lin HY, Liu GY, Li QL \& Zhu C 2004 Regulation of matrix metalloproteinases (MMPS) and their inhibitors (TIMPS) during mouse peri-implantation: role of nitric oxide. Placenta 25 243-252.

Received 18 November 2005

First decision 11 January 2006

Revised manuscript received 16 May 2006

Accepted 26 June 2006 